\title{
Computationally Probing the Performance of Hybrid, Heterogeneous, and Homogeneous Iridium-Based Catalysts for Water Oxidation
}

\author{
Max García-Melchor, ${ }^{*[a]}$ Laia Vilella, ${ }^{[\mathrm{b}, \mathrm{c}]}$ Núria López, ${ }^{[\mathrm{b}]}$ and Aleksandra Vojvodic ${ }^{[\mathrm{d}]}$
}

An attractive strategy to improve the performance of water oxidation catalysts would be to anchor a homogeneous molecular catalyst onto a heterogeneous solid surface to create a hybrid catalyst. The idea of this combined system is to take advantage of the individual properties of each of the two catalyst components. We use DFT calculations to determine the stability and activity of a model hybrid water oxidation catalyst that consists of a dimeric Ir complex attached on the $\operatorname{IrO}_{2}\left(\begin{array}{ll}1 & 10\end{array}\right.$ surface through two oxygen atoms. We find that homogeneous catalysts can be anchored to oxide surfaces without a significant loss of activity. Hence, the design of hybrid systems that benefit from both the high tunability of the activity of homogeneous catalysts and the stability of heterogeneous systems seems feasible.

\section{Introduction}

With the depletion of fossil fuels and the environmental concerns over their use, there is an increasing need to replace these energy sources with more sustainable and renewable ones. ${ }^{[1,2]}$ One promising solution would be to use electrical energy from a renewable source, for example, sunlight and store it in the form of chemical bonds such as $\mathrm{H}_{2}$ and $\mathrm{O}_{2}$ through artificial photosynthesis. ${ }^{[3,4]}$ The bottleneck of this process is the oxidation of water to molecular oxygen, also known as the oxygen evolution reaction (OER). ${ }^{[5]}$ This reaction is particularly energy demanding because of the mechanistic requirements for the removal of four electrons and protons from two water molecules with the concomitant formation of an $\mathrm{O}$ O bond. ${ }^{[6,7]}$ Hence, the search for active OER catalysts that provide high current densities and operate for substantial periods of time without degradation has been a quest for decades. To

[a] Dr. M. García-Melchor

SUNCAT Center for Interface Science and Catalysis

Department of Chemical Engineering

Stanford University

Stanford, CA 94305 (USA)

E-mail:maxg@slac.stanford.edu

[b] Dr. L. Vilella, Prof. N. López

Institute of Chemical Research of Catalonia (ICIQ)

The Barcelona Institute of Science and Technology (BIST)

Av. Països Catalans, 16, E-43007 Tarragona (Spain)

[c] Dr. L. Vilella

Departament de Química

Universitat Autònoma de Barcelona

Cerdanyola del Vallès, E-08193 Barcelona (Spain)

[d] Dr. A. Vojvodic

SUNCAT Center for Interface Science and Catalysis

SLAC National Accelerator Laboratory

Menlo Park, CA 94025 (USA)

E-mail: alevoj@slac.stanford.edu

$\square$ Supporting Information and the ORCID identification number(s) for the
(D) author(s) of this article can be found under http://dx.doi.org/10.1002/ cctc. 201600007. date, the best homogeneous and heterogeneous OER catalysts are based on Ir and $\mathrm{Ru}_{1}{ }^{[8-11]}$ but the scarcity and high cost of these elements limit the scale-up of the energy conversion technologies. ${ }^{[12]}$ In addition, even the most active Ir- and Rubased catalysts reported in the literature either require a high overpotential or are not stable enough for industrial application. To overcome these issues, several approaches have been undertaken such as the synthesis of catalysts inspired by nature ${ }^{[13-15]}$ and based on non-precious metals, ${ }^{[16-19]}$ the addition of dopants ${ }^{[20-23]}$ or promoters, ${ }^{[22,24,25]}$ or the creation of confined reaction environments. ${ }^{[26,27]}$

Another appealing strategy, which is far from fully exploited yet, consists of the anchoring of active homogeneous OER catalysts on a solid support (either active or inactive) to create a hybrid type of catalyst. ${ }^{[28-30]}$ The fundamental idea behind these combined systems is that they might benefit from the individual properties of their homogeneous and heterogeneous constituents, as the limitations of one are usually the main advantages of the other. ${ }^{[31]}$ Homogeneous catalysts typically exhibit a high tunability of activity but they lack the high stability and good electron transport often found in heterogeneous catalyst systems. Besides the coexistence of these benefits, a synergistic effect that arises from a combination of the two catalytic systems might also emerge. To date, a few successful examples of this strategy have been demonstrated, which include the recent experimental studies on water oxidation using an Ir-based HEDTA (HEDTA = monoprotonated ethylenediaminetetraacetic acid) catalyst supported on $\mathrm{TiO}_{2}{ }^{[32]}$ and a dimeric Ir complex anchored on Sn-doped indium oxide nanoparticles. ${ }^{[33]}$ However, the interplay between the anchored molecular catalyst and the support is still unknown.

Herein, we present the first DFT study on the OER performance (stability and activity) of a hybrid model Ir-based catalyst (Figure $1 \mathrm{a}$ ) and compare it to its corresponding homogeneous and heterogeneous constituents (Figure $1 \mathrm{~b}-\mathrm{c}$ ). Our cal- 

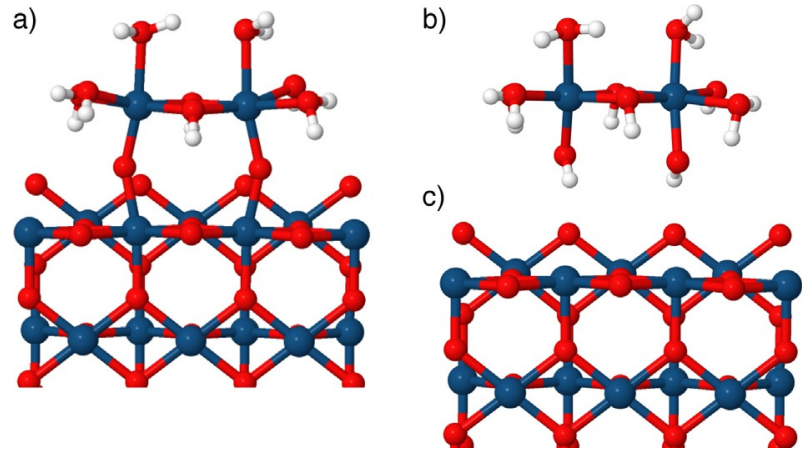

Figure 1. Side view of the atomic structure for the investigated a) hybrid, b) homogeneous, and c) heterogeneous Ir-based catalysts. Color code: Ir (dark blue), $\mathrm{O}$ (red), and $\mathrm{H}$ (white). This color code applies to all subsequent figures.

culations show that the homogeneous catalyst binds strongly to the support surface and performs water oxidation without a significant loss of activity. We also identify the active site motifs and reaction pathways for each catalytic system, and based on that, propose that tuning the chemical properties of the surface can be used as a complementary approach to the metal-ligand exchange to alter the OER performance. These results may pave the way to design more efficient and robust water oxidation catalysts.

\section{Computational Details}

The stability and OER activity of the considered Ir-based catalysts were investigated by using DFT calculations in conjunction with the computational standard hydrogen electrode (SHE) model. ${ }^{[34]}$ All the calculations were performed using the Perdew-Burke-Ernzenhof ${ }^{[35]}$ (PBE) exchange correlation functional as implemented in the VASP code, version 5.3.2. ${ }^{[36,37]}$ Unless otherwise indicated, the core electrons of the Ir, $\mathrm{O}$, and $\mathrm{H}$ atoms have been replaced by projector-augmented wave (PAW) pseudopotentials, ${ }^{[38]}$ whereas their valence electrons have been expanded in plane waves with a kinetic energy cutoff of $450 \mathrm{eV}$.

The lattice parameters for the bulk rutile $\mathrm{IrO}_{2}$ structure have been optimized using a higher cutoff energy of $600 \mathrm{eV}$ and a $9 \times 9 \times 13$ Monkhorst Pack (MP) k-point grid. The obtained lattice parameters are $a_{\text {calc }}=b_{\text {calc }}=4.543 \AA$ and $c_{\text {calc }}=3.187 \AA$, which are in very good agreement with previous theoretical finding $\mathrm{s}^{[39,40]}$ and experimental values $\left(a_{\exp }=b_{\exp }=4.505 \AA\right.$ and $\left.c_{\text {exp }}=3.159 \AA\right) .{ }^{[41]}$ To model the heterogeneous $\operatorname{IrO}_{2}$ catalyst surface, we used a $2 \times 1$ supercell that consisted of a slab of nine atomic layers of the most stable (110) facet ${ }^{[42]}$ separated by at least $13 \AA$ of vacuum. Geometry optimizations for this system were performed by using a $5 \times 5 \times 1 \mathrm{MP}$ k-point mesh and by allowing the adsorbed species $\left(\mathrm{O}^{*}, \mathrm{HOO}^{*}, \mathrm{OO}^{*}, \mathrm{H}_{2} \mathrm{O}^{*}\right.$, and $\mathrm{HO}^{*}$, in which the asterisk corresponds to an active site on the oxide) and the five topmost atomic layers to relax, and the rest of the atoms were kept fixed at their bulk positions.

In the case of the homogeneous catalyst, we simulated the dimeric complex $\left[\mathrm{Ir}_{2}\left(\mathrm{H}_{2} \mathrm{O}\right)_{4}(\mathrm{OH})_{4}(\mu-\mathrm{OH})_{2}\right]$ using a cell of $18 \times 15 \times$
$15 \AA$ in size and sampling the Brillouin zone at the $\Gamma$-point. This charge-neutral compound avoids the complexity of dealing with charged species in periodic calculations. To model the hybrid catalyst, we anchored this dimeric Ir complex on top of the $\operatorname{IrO}_{2}(110)$ surface with a $6 \times 2$ periodicity through two oxygen atoms to the coordinatively unsaturated sites (CUS) sites of the surface. As a result of the considerable size of the combined system, calculations for this catalyst were performed at the $\Gamma$-point. The energy convergence with respect to the kpoint sampling was examined for selected adsorbed species using a denser $2 \times 3 \times 1$ k-point mesh, which obtained energy differences within $0.02 \mathrm{eV}$ (Table S1). Geometry optimizations for the hybrid catalyst were performed by relaxing the OER intermediates, the atoms in the attached dimer, and the three topmost surface layers.

For the three model Ir catalysts, total energies were converged to values less than $10^{-5} \mathrm{eV}$ in the self-consistent field, and the geometries were relaxed until the energy threshold of $10^{-4} \mathrm{eV}$ was fulfilled. The nature of all stationary points was confirmed by calculating the vibrational frequencies of the adsorbed species and metal atoms coordinated directly to them. Contributions to the Gibbs energies for the adsorbates were calculated at $T=300 \mathrm{~K}$ and $p=1 \mathrm{~atm}$, except for water, for which the equilibrium vapor pressure at that temperature ( $p=$ $0.035 \mathrm{~atm}$ ) was used (see Supporting Information for details). The Gibbs energy for the water oxidation reaction was fixed to the experimentally known value of $4.92 \mathrm{eV}$ to avoid the introduction of the DFT error into the energetics related to molecular oxygen. ${ }^{[34,43,44]}$ Spin-polarized calculations were performed if needed, relaxing the total magnetic moment during the selfconsistent cycles.

\section{Results and Discussion}

In this work, we investigate the viability of a hybrid water oxidation catalyst and the role of the surface in this type of system by anchoring the Ir complex $\left[\mathrm{Ir}_{2}\left(\mathrm{H}_{2} \mathrm{O}\right)_{4}(\mathrm{OH})_{4}(\mu-\mathrm{OH})_{2}\right]$ on the $\mathrm{IrO}_{2}(110)$ surface through two oxygen atoms as linkers (Figure 1). We chose this dimeric Ir complex as the homogeneous catalyst (Ir-hom) because it resembles the molecular species suggested to be involved in the formation of the purpleblue solution that catalyzes water oxidation. ${ }^{[4]}$ Moreover, such a dimeric complex allows us to compare the two main OER mechanisms proposed in the literature, namely, the water nucleophilic attack (WNA) and the interaction between two M-O units (I2M) ${ }^{[11,46,47]}$ In addition, we selected $\mathrm{IrO}_{2}$ (Ir-het) as the heterogeneous catalyst because it is one of the most active pure single transition metal oxides reported to date $\mathrm{e}^{[9,48]}$ and it has been studied computationally in detail. ${ }^{[49-51]}$

Notably, the hybrid catalyst considered in this work (Ir-hyb) is intended to serve as a model to probe the feasibility and mechanisms of this type of system and should not be considered as a potential high-performance OER catalyst. With this aim, we first examine the stability of Ir-hyb by calculating the adsorption energy of the dimeric $\mathrm{Ir}$ complex to the $\operatorname{IrO}_{2}(110)$ surface as follows [Eq. (1)]: 
$\Delta E_{\text {ads }}=E_{\mathrm{H}_{2}}+E_{\mathrm{lr} \text {-hyb }}-E_{\mathrm{lr} \text {-hom }}-E_{\mathrm{lr} \text {-het }}$

in which $E_{\mathrm{H}_{2}}, E_{\mathrm{Ir} \text {-hybr }}, E_{\mathrm{Ir} \text {-hom, }}$ and $E_{\mathrm{Ir} \text {-het }}$ are the potential energies for molecular hydrogen and the Ir-hyb, Ir-hom, and Ir-het systems, respectively. Importantly, the obtained adsorption energy from Equation (1) is exothermic by $2.19 \mathrm{eV}$, which indicates that the dimeric Ir complex is indeed attached strongly to the $\mathrm{IrO}_{2}(110)$ surface through the two oxygen linkers. Interestingly, the optimized Ir-Ir bond distance in the attached Ir dimer almost matches that of the $\operatorname{IrO}_{2}(110)$ surface $(3.207$ vs. $3.190 \AA$ ). . Hence, this particular hybrid catalyst that contains only aqua and hydroxo ligands might be conceived as a defect on the surface, or an extension of the $\operatorname{IrO}_{2}(110)$ surface, which would explain the strong interaction between the homogeneous and heterogeneous constituents predicted by calculations, or even possibly a crude model for amorphous $\mathrm{IrO}_{x}$. Further insight into this interaction can be gained by evaluating the electronic charge density difference between the molecular and the surface fragments of the Ir-hyb catalyst (Figure S1). This analysis reveals that both Ir atoms from the adsorbed complex and the surface provide electron density to the $\mathrm{O}$ linkers, which makes these bonds rather strong.

We also examine the stability of Ir-hyb by calculating the energy required to detach the dimeric Ir complex from the surface upon the attack of two solvent water molecules, $\Delta E_{\text {des }}$ according to Equation (2):

$\Delta E_{\text {des }}=E_{\mathrm{lr} \text {-het }+2 \mathrm{OH}}+E_{\mathrm{lr} \text {-hom }}-2^{*} E_{\mathrm{H}_{2} \mathrm{O}}-E_{\mathrm{lr}-\text { hyb }}$

in which $E_{\mathrm{H}_{2} \mathrm{O}}$ and $E_{\mathrm{Ir} \text {-het+2OH }}$ are the energies for a water gas molecule and the $\operatorname{IrO}_{2}(110)$ surface with two $\mathrm{OH}$ groups adsorbed at CUS positions, respectively. In this case, we find that the deactivation route in Equation (2) is a highly endothermic process $(1.54 \mathrm{eV})$, which reinforces the stability of the Ir-hyb system.

Before we evaluated the OER activity for Ir-hyb and its individual constituents, it is necessary to determine the resting state of the catalyst under relevant reaction conditions. To this end, for each catalytic system we examined a number of potential species that might exist in aqueous solution. More specifically, for the Ir-het catalyst we considered up to 19 different $\mathrm{H}, \mathrm{O}$, and $\mathrm{OH}$ surface coverages (Figure S2) and calculated their relative Gibbs energies as a function of $\mathrm{pH}$ and applied voltage $(U)$ to construct a surface Pourbaix diagram. According to the Pourbaix representation (Figure $2 \mathrm{a}$ ), the resting state for Ir-het under typical OER conditions corresponds to a surface with all Ir-CUS sites covered completely by $\mathrm{O}$ atoms, in agreement with previous theoretical findings. ${ }^{[27,49]}$

Unlike the heterogeneous system, the assessment of the resting state for Ir-hom is significantly more complicated given the vast number of possible protonation states of this complex. However, a thorough analysis of the resting state for this system is still necessary. Here, we tackle this issue by first exploring several consecutive dehydrogenation of Ir-hom at a thermodynamic potential of $1.23 \mathrm{~V}$ and $\mathrm{pH} 0$ (Figure S3). Under these conditions, calculations indicate that aqua ligands are dehydrogenated preferentially until a fully hydroxylated di-
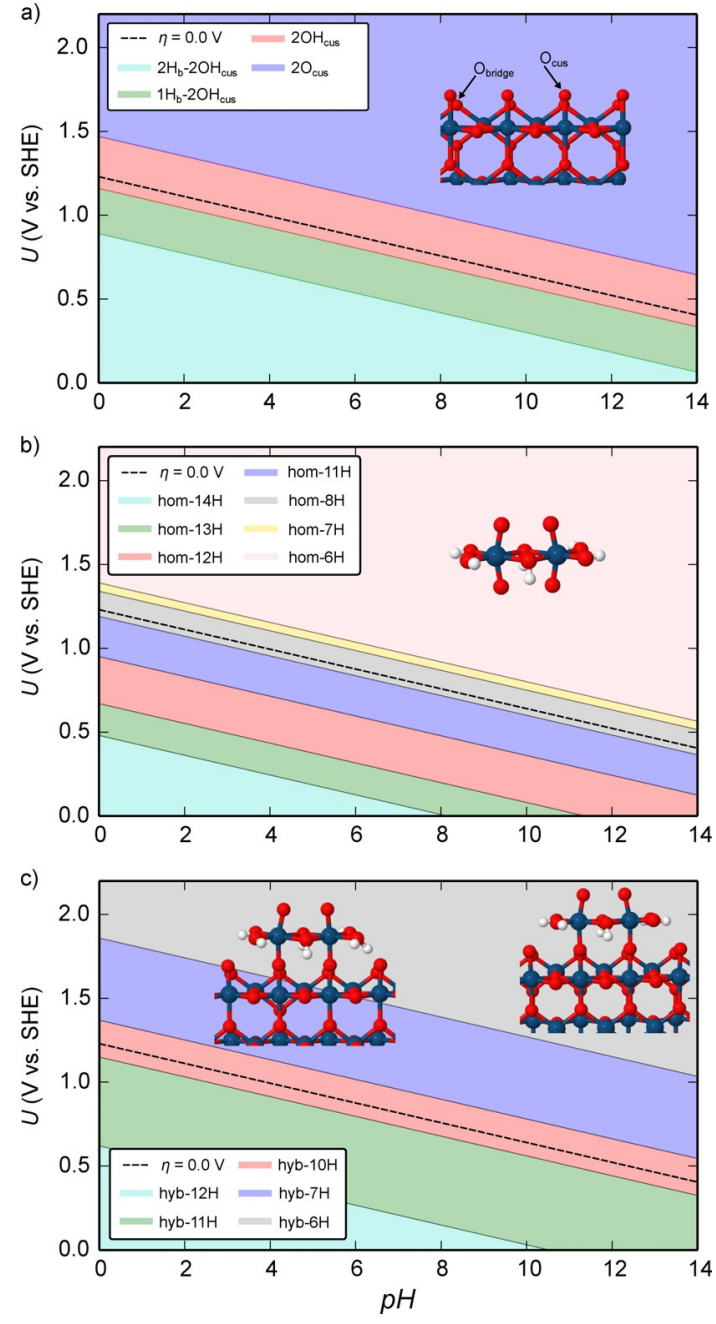

Figure 2. Calculated Pourbaix diagrams for the model a) Ir-het, b) Ir-hom, and c) Ir-hyb catalysts. Insets of the most relevant structures are shown. The coverages for the Ir-het system are labeled as $\mathrm{mH}_{\mathrm{b}}-n \mathrm{nH}_{\text {cus }}-\mathrm{kO}_{\text {cus }}$ in which $m \mathrm{H}_{\mathrm{b}}$ is the number of $\mathrm{H}$ atoms at the $\mathrm{O}_{\text {bridge }}$ positions, and $m \mathrm{OH}_{\text {cus }}$ and $k \mathrm{O}_{\text {cus }}$ are the number of $\mathrm{OH}$ and $\mathrm{O}$ groups in CUS positions. Structures for the Irhom and Ir-hyb systems are named as $n \mathrm{H}$, in which $n$ is the total number of $\mathrm{H}$ atoms contained in each system.

meric $\mathrm{Ir}^{\mathrm{V}}$ species is obtained (Figure S4). From this complex, we have further examined all possible isomers with different hydrogen contents and formal Ir oxidation states up to +7 (Figure S5). Notably, the existence of $\mathrm{IrO}_{4}$ and $\left[\mathrm{IrO}_{4}\right]^{+}$species with oxidation states of +8 and +9 have been reported, ${ }^{[52,53]}$ although they have only been characterized in rare-gas matrices. Therefore, we are only taking into account Ir species with oxidation states up to +7 . The Pourbaix diagram constructed if we consider all the above dimeric Ir complexes (Figure $2 \mathrm{~b}$ ) shows that Ir-hom under OER overpotentials has a total of six $\mathrm{H}$ atoms and corresponds to a symmetric $\mathrm{Ir}^{\mathrm{VII} /} / \mathrm{Ir}^{\mathrm{VII}}$ dimer with only hydroxo and oxo ligands in the equatorial and axial planes, respectively.

As a result of the considerable size of the Ir-hyb catalyst and the large number of possible protonation states of the adsorbed dimeric Ir complex, for this system we assume the same surface coverage as obtained for Ir-het (Figure 2a); that 
is, a surface with the CUS sites covered fully by $\mathrm{O}$ atoms. As far as the resting state of the anchored Ir dimer is concerned, we have considered the same consecutive dehydrogenation as investigated for Ir-hom (Figure S3). Based on all these structures and several further oxidized species with formal Ir oxidation states up to +6 (Figure S6), we have constructed the Pourbaix diagram shown in Figure $2 c$. We find that there are two Ir-hyb species that might exist at relevant OER potentials (Figure $2 c$, insets). The first one, stable at lower overpotentials, contains seven $\mathrm{H}$ atoms and corresponds to an Ir species in which the equatorial plane is fully hydroxylated except for one position that has an aqua ligand. The second one (denoted hyb-6 H) is stable at slightly higher overpotentials and is analogous to the resting state found for Ir-hom. Interestingly, the potentials required to reach the same Ir oxidation states in Ir-hyb are significantly higher than those needed for Ir-hom, which suggests that the Ir atoms of Ir-hyb are less prone to be oxidized. We also find that, in contrast to the Ir-hom catalyst, the aqua ligands in the equatorial positions of Ir-hyb are more difficult to dehydrogenate because of the formation of $\mathrm{H}$ bonds between these ligands and the $\mathrm{O}_{\text {cus }}$ surface atoms.

We next evaluate the OER activity for the Ir-het, Ir-hom, and Ir-hyb catalysts based on the resting states derived from the Pourbaix diagrams (Figure 2). To compare the activity of these three catalytic systems, for each of them we have determined the potential-limiting step, defined as the onset potential at which all the OER steps become thermodynamically downhill. The difference between the limiting and the standard water oxidation potentials is the theoretical overpotential, $\eta$ [Eq. (3)]: : $:^{[43,49,34]}$

$\eta=\max \left(\Delta G_{i} / e\right)-1.23 \mathrm{~V}$

For rutile oxides, water oxidation in an acidic medium has been proposed to occur through a WNA mechanism, ${ }^{[49,54,55]}$ which consists of the following four electrochemical steps (WNA-1; Figure $3 \mathrm{a}$ ):
1) $\mathrm{H}_{2} \mathrm{O}_{(\mathrm{I})}+\mathrm{O}^{*} \rightarrow \mathrm{HOO}^{*}+\mathrm{e}^{-}+\mathrm{H}^{+}$
2) $\mathrm{HOO}^{*} \rightarrow \mathrm{O}_{2(\mathrm{~g})}+{ }^{*}+\mathrm{e}^{-}+\mathrm{H}^{+}$
3) ${ }^{*}+\mathrm{H}_{2} \mathrm{O}_{(1)} \rightarrow \mathrm{HO}^{*}+\mathrm{e}^{-}+\mathrm{H}^{+}$
4) $\mathrm{HO}^{*} \rightarrow \mathrm{O}^{*}+\mathrm{e}^{-}+\mathrm{H}^{+}$

However, one variant of this mechanism would be to replace step 2) and 3) by the following alternative steps that do not entail unsaturated octahedral Ir atoms at the surface (WNA-2, Figure 3 a):

$$
\begin{aligned}
& \left.2^{\prime}\right) \mathrm{HOO}^{*} \rightarrow \mathrm{OO}^{*}+\mathrm{e}^{-}+\mathrm{H}^{+} \\
& \left.3^{\prime}\right) \mathrm{OO}^{*}+\mathrm{H}_{2} \mathrm{O}_{(\mathrm{I})} \rightarrow \mathrm{O}_{2(\mathrm{~g})}+\mathrm{HO}^{*}+\mathrm{e}^{-}+\mathrm{H}^{+}
\end{aligned}
$$

In this case, a proton-coupled-electron transfer (PCET) reaction from the $\mathrm{HOO}^{*}$ intermediate yields a molecularly adsorbed OO* species that subsequently evolves to molecular oxygen
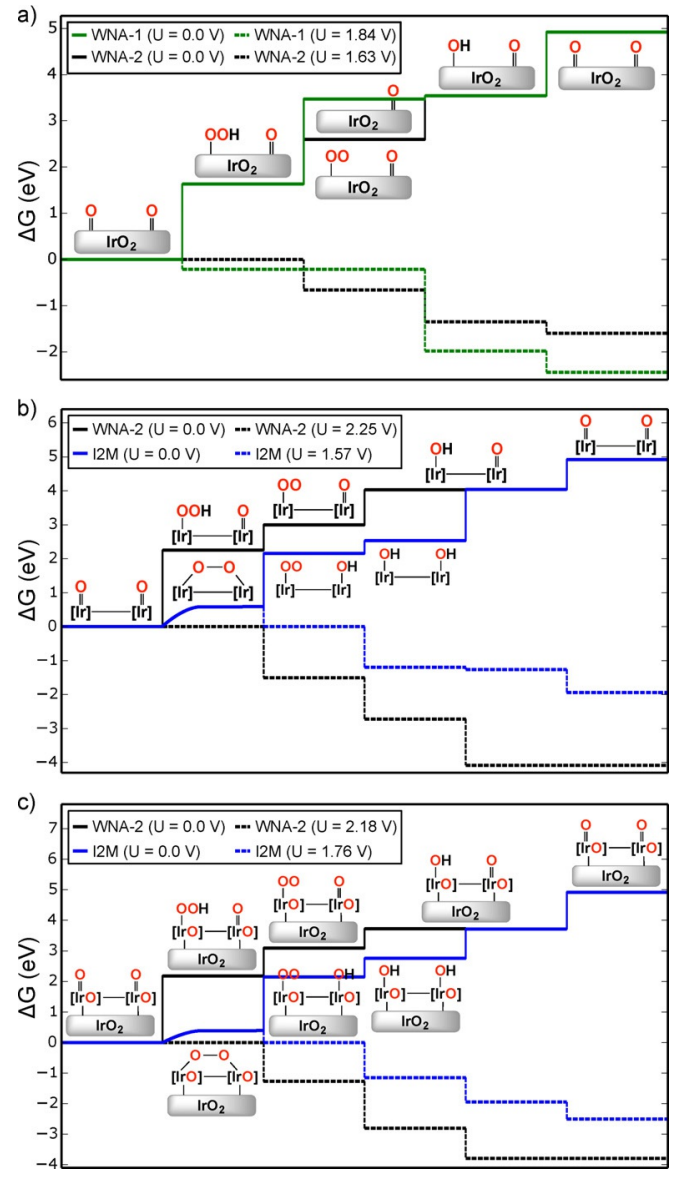

Figure 3. Gibbs energy diagrams for the OER activity of the a) Ir-het, b) Irhom, and c) Ir-hyb (with six $\mathrm{H}$ atoms) catalysts through the conventional and alternative WNA (green and black lines, respectively) and I2M (blue lines) mechanisms.

and a $\mathrm{HO}^{*}$ group generated by a second PCET. According to our calculations, the thermodynamically most energy-demanding step in the WNA-1 mechanism corresponds to $\mathrm{O}_{2}$ desorption, whereas in the WNA-2 it is the generation of the $\mathrm{HOO}^{*}$ species (step 1), which involves the formation of the $\mathrm{O}-\mathrm{O}$ bond. These reaction steps result in overpotentials of 0.61 and $0.40 \mathrm{~V}$ for the conventional WNA-1 and alternative WNA-2 mechanisms, respectively (Figure $3 \mathrm{a}$ ). Thus, this alternative pathway is more favorable by $0.21 \mathrm{~V}$, and therefore, we will consider this mechanism to compare the OER performance of Ir-het with the other model catalysts. Moreover, the calculated overpotential of $0.40 \mathrm{~V}$ through the WNA-2 mechanism is in agreement with the reported experimental value of $0.36 \mathrm{~V}$ at a current density of $10 \mathrm{~mA} \mathrm{~cm}^{-2}$. [9]

For homogeneous water oxidation catalysts, both the WNA and $12 \mathrm{M}$ reaction mechanisms have been shown to operate, which depends on the nature of the catalyst. ${ }^{[47]}$ Thus, for Irhom we have explored these two mechanisms and several variants of thereof (Figure S7). In the case of the WNA mechanism, we find that the lowest energy pathway is the same as that for Ir-het (WNA-2; Figure $3 \mathrm{a}$ ), in which the $\mathrm{O}^{*} \rightarrow \mathrm{HOO}^{*}$ transition is the potential-limiting step (Figure $3 \mathrm{~b}$ ). Nevertheless, the calcu- 
lated theoretical overpotential for Ir-hom is significantly higher, that is, $1.02 \mathrm{~V}$, than that of Ir-het.

However, the lowest energy path obtained for the I2M mechanism consists of the following steps:

$$
\begin{aligned}
& \text { 1) } \mathrm{O}^{*}+\mathrm{O}^{*} \rightarrow{ }^{*} \mathrm{OO}^{*} \\
& \text { 2) }{ }^{*} \mathrm{OO}^{*}+\mathrm{H}_{2} \mathrm{O}_{(\mathrm{I})} \rightarrow \mathrm{OO}^{*}+\mathrm{HO}^{*}+\mathrm{e}^{-}+\mathrm{H}^{+} \\
& \text {3) } \mathrm{OO}^{*}+\mathrm{HO}^{*}+\mathrm{H}_{2} \mathrm{O}_{(\mathrm{l})} \rightarrow 2 \mathrm{HO}^{*}+\mathrm{O}_{2(\mathrm{~g})}+\mathrm{e}^{-}+\mathrm{H}^{+} \\
& \text {4) } 2 \mathrm{HO}^{*} \rightarrow \mathrm{HO}^{*}+\mathrm{O}^{*}+\mathrm{e}^{-}+\mathrm{H}^{+} \\
& \text {5) } \mathrm{HO}^{*} \rightarrow \mathrm{O}^{*}+\mathrm{e}^{-}+\mathrm{H}^{+}
\end{aligned}
$$

This mechanism starts with the coupling between two iridium bis-oxo moieties that lead to a $\mu$-1,2-peroxo intermediate (Figure $3 \mathrm{~b}$ ). From this species, the cleavage of one $\mathrm{Ir}-\mathrm{O}$ bond is promoted by the nucleophilic attack of a water molecule to result in the formation of a superoxide and an $\mathrm{OH}$ group generated by PCET. This superoxide species subsequently evolves to molecular oxygen with the coordination of a second water molecule, which gives rise to an $\mathrm{OH}$ group through a second PCET. Finally, the starting bis-oxo species is regenerated after two consecutive PCET reactions to complete the catalytic cycle.

The potential at which all the electrochemical steps in the I2M mechanism become downhill in energy is $1.57 \mathrm{~V}$ (Figure $3 \mathrm{~b}$ ). However, a calculation of the transition state for the I2M mechanism reveals an activation barrier of $0.76 \mathrm{eV}$. Notably, this chemical step is not affected by the applied bias. The surmountable barrier together with the fact that the overpotential for the $12 \mathrm{M}$ mechanism is much lower than that of the WNA-2 (0.34 vs. $1.02 \mathrm{~V}$ ) suggests that these two mechanisms are at least competitive at a certain temperature.

For the Ir-hyb catalyst, analysis of the Pourbaix diagram suggests the existence of two different resting states in the range of typical OER overpotentials (purple and gray regions in Figure $2 \mathrm{c}$ ). Therefore, we have examined the activity of these two species by considering both the WNA and I2M mechanisms for each of them. For the two species, we find the same lowest energy paths and potential-limiting steps as for the Ir-hom system (Figure S7). In particular, for the Ir-hyb species that contains seven $\mathrm{H}$ atoms, we find that all the electrochemical steps in the WNA-2 and I2M mechanisms are downhill in energy at potentials of 2.24 and $1.50 \mathrm{~V}$, respectively (Figure S8). However, the $12 \mathrm{M}$ mechanism is hampered by the high chemical energy required to form the $\mu-1,2$-peroxo intermediate $(0.98 \mathrm{eV})$.

However, for the Ir-hyb species with six $\mathrm{H}$ atoms, all the electrochemical steps in the WNA-2 and I2M mechanisms become downhill at 2.18 and $1.76 \mathrm{~V}$, respectively. In this case, we find that the formation energy for the $\mu-1,2$-peroxo intermediate is rather low $(0.39 \mathrm{eV})$, and therefore, it may be surpassed even at room temperature. Based on these thermodynamic data, we predict that the I2M mechanism for this species may be more favorable than WNA-2. In other words, the height of the chemical step and the overpotential for the WNA-2 mechanism for this species are lower than that of the one that contains seven
$\mathrm{H}$ atoms, which suggests that Ir-hyb with six $\mathrm{H}$ atoms may be more representative for the OER activity of this catalyst.

Taken together, our results show that the intrinsic OER activity of the different model Ir-based catalysts through a WNA-2 mechanism increases as follows: Ir-hom $\approx$ Ir-hyb $<$ Ir-het. With regards to the $12 \mathrm{M}$ mechanism, the comparison between the Ir-hom and Ir-hyb systems is more complicated because of the concurrence of electrochemical and chemical reaction steps. Nevertheless, the fact that Ir-hom requires a slightly lower overpotential compared to Ir-hyb (0.34 vs. $0.53 \mathrm{~V})$ but a higher chemical barrier ( 0.59 vs. $0.39 \mathrm{eV}$ ) indicates that these two catalysts might exhibit a comparable OER activity. The comparison of the overall activity between the three model Ir-based catalysts is also rather complex, as the lowest energy-demanding pathway for both Ir-hom and Ir-hyb is the I2M mechanism, which involves a chemical step, whereas for Ir-het it is the WNA-2 mechanism. If we assume low energy barriers for the chemical steps for Ir-hom and Ir-hyb, the activity trend is then dictated by the applied overpotential: Ir-hom $>$ Ir-het $>$ Ir-hyb. Although this trend is not conclusive, the high OER activity predicted for Ir-hom would support that this species might be part of the purple-blue solution as suggested by Crabtree et al. ${ }^{[45]}$ However, the same authors also proposed that this species eventually forms $\mathrm{IrO}_{2}$ nanoparticles, and thus it might not be very stable in aqueous solution.

Finally, to shed light on the role of the surface in Ir-hyb, we performed the Bader charge analyses presented in Figure 4.
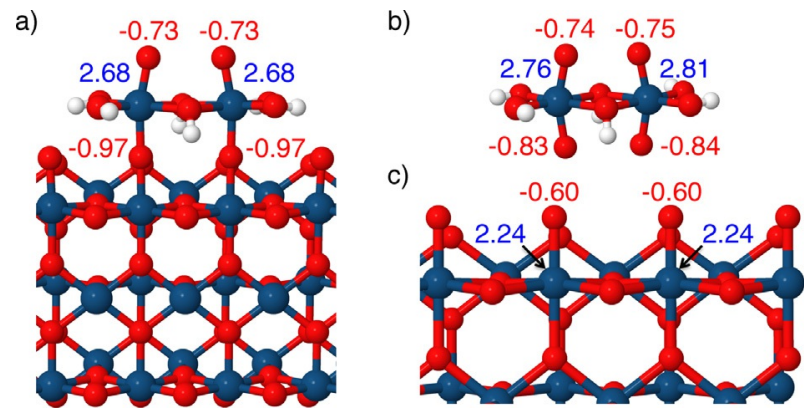

Figure 4. Calculated oxygen (red) and iridium (blue) Bader charges for the resting states of the a) Ir-hyb, b) Ir-hom, and c) Ir-het catalysts.

We find that the electronic charge of the $\mathrm{O}$ atoms in the resting states of the different Ir-based catalysts (top axial oxo groups) increase in the order: $\left|q_{\text {Ir-het }}\right|<\left|q_{\text {Ir-hyb }}\right| \approx\left|q_{\text {Ir-hom }}\right|$. This indicates that the oxo moieties in the Ir-hyb and Ir-hom catalysts are less electrophilic than that in Ir-het. Consequently, the oxo groups in Ir-hom and Ir-hyb are less reactive towards the nucleophilic attack of a water molecule, which accounts for the predicted activity trend through the WNA-2 mechanism. In addition, we find that the charge of the Ir atoms of the active site varies within the different model catalysts, which points to an increase in oxidation state as follows: Ir-het $<$ Ir-hyb $<$ Irhom. This trend is tightly coupled to the electronic charge of the $\mathrm{O}$ atoms involved in the reaction. We also observe that the charge of the $\mathrm{O}$ linkers of Ir-hyb and the bottom oxo moieties 
in Ir-hom (Figure $4 \mathrm{a}$ and b) are similar, which suggests that the former behave more similarly to oxo ligands than to hydroxo groups (Figure S9). This can be ascribed to the additional charge donation provided by the $\operatorname{IrO}_{2}(110)$ surface to the $\mathrm{O}$ linkers in the Ir-hyb catalyst.

\section{Conclusions}

In this work, we employed DFT calculations to evaluate the viability of a hybrid water oxidation catalyst generated by attaching a dimeric Ir complex (Ir-hom) to the $\mathrm{IrO}_{2}(110)$ surface (Irhet). Our results indicate that the interaction between the adsorbed catalyst and the surface is rather strong as a result of the electron donation from both Ir atoms in the anchored complex and the surface to the $O$ linkers. The oxygen evolution reaction (OER) activity of the hybrid catalyst (Ir-hyb) is further assessed and compared to its constituent fragments. The activity trend for the water nucleophilic attack (WNA) mechanism is Ir-hom $\approx$ Ir-hyb $<$ Ir-het. If we assume that the chemical barriers in the interaction between two $\mathrm{M}-\mathrm{O}$ units (I2M) mechanism for Ir-hom and Ir-hyb systems are feasible under OER conditions, the catalytic activity may be governed by the applied potential to result in the trend: Ir-hom $>$ Ir-het $>\mid$ r-hyb. This is supported by the calculated activation barrier for the I2M mechanism with Ir-hom, which should be surmountable at room temperature. The high activity of Ir-hom shown in our calculations is consistent with the similar structures suggested to be involved in the formation of the purple-blue solution. ${ }^{[45]}$ Importantly, our calculations predict no significant activity loss if the dimeric Ir complex is anchored on the $\operatorname{IrO}_{2}(110)$ surface through $\mathrm{O}$ atoms. Thus, by attaching the dimeric Ir complex to an $\operatorname{IrO}_{2}(110)$ surface through $\mathrm{O}$ linkers, the stability of the homogeneous catalyst might be enhanced, as calculations show that this interaction is very strong.

Taken together, the results reported herein are encouraging as they suggest that hybrid catalysts are not only viable but they might also benefit from the activity of homogeneous catalysts and the stability of heterogeneous ones. Our findings are in line with recent experimental findings for a stable and water-oxidation-active dimeric Ir complex anchored on a metal oxide surface. ${ }^{[33]}$ The here demonstrated phenomena for a hybrid system based on iridium oxide should be generalized to more affordable materials. Furthermore, our findings suggest that there is ample room to improve the catalytic performance of hybrid catalysts by fine-tuning the ligands of the homogeneous constituent and the electrochemical properties of the heterogeneous constituent.

\section{Acknowledgements}

The authors acknowledge support from the DOE Office of Basic Energy Science to the SUNCAT Center for Interface Science and Catalysis and SLAC National Accelerator Laboratory LDRD program. M.G.-M. acknowledges funding from the Agency for Administration of University and Research Grants of Catalonia (AGAUR, 2013 BP-A 00464). L.V. acknowledges funding from
MINECO (CTQ2014-54071-P) and MECD (FPU fellowship). N.L. acknowledges funding from funding from ICIQ and computational resources from BSC-RES. The authors would like to thank Prof. Jens K. Nørskov and Dr. Michal Bajdich for helpful discussions.

Keywords: density functional theory - heterogeneous catalysis • homogeneous catalysis . iridium • reaction mechanisms

[1] T. B. Johansson, Renewable energy: sources for fuel and electricity, Island press, Washington, D.C., 1993.

[2] R. Pike, P. Earis, Energy Environ. Sci. 2010, 3, 173.

[3] D. Gust, T. A. Moore, A. L. Moore, Acc. Chem. Res. 2009, 42, 1890-1898.

[4] K. S. Joya, Y. F. Joya, K. Ocakoglu, R. van de Krol, Angew. Chem. Int. Ed. 2013, 52, 10426-10437; Angew. Chem. 2013, 125, 10618-10630.

[5] I. Katsounaros, S. Cherevko, A. R. Zeradjanin, K. J. J. Mayrhofer, Angew. Chem. Int. Ed. 2014, 53, 102-121; Angew. Chem. 2014, 126, 104-124.

[6] H. Dau, C. Limberg, T. Reier, M. Risch, S. Roggan, P. Strasser, ChemCatChem 2010, 2, 724-761.

[7] H. Inoue, T. Shimada, Y. Kou, Y. Nabetani, D. Masui, S. Takagi, H. Tachibana, ChemSusChem 2011, 4, 173-179.

[8] L. Duan, F. Bozoglian, S. Mandal, B. Stewart, T. Privalov, A. Llobet, L. Sun, Nat. Chem. 2012, 4, 418-423.

[9] C. C. L. McCrory, S. Jung, I. M. Ferrer, S. M. Chatman, J. C. Peters, T. F. Jaramillo, J. Am. Chem. Soc. 2015, 137, 4347-4357.

[10] J. D. Blakemore, R. H. Crabtree, G.W. Brudvig, Chem. Rev. 2015, 115, $12974-13005$.

[11] A. Llobet, Molecular Water Oxidation Catalysis, Wiley, West Sussex, UK, 2014.

[12] P. C. K. Vesborg, T. F. Jaramillo, RSC Adv. 2012, 2, $7933-7947$.

[13] R. Tagore, R. H. Crabtree, G. W. Brudvig, Inorg. Chem. 2008, 47, 1815 1823.

[14] C. S. Mullins, V. L. Pecoraro, Coord. Chem. Rev. 2008, 252, 416-443.

[15] C. Zhang, C. Chen, H. Dong, J.-R. Shen, H. Dau, J. Zhao, Science 2015, 348, 690-693.

[16] M. W. Kanan, D. G. Nocera, Science 2008, 321, 1072-1075.

[17] P. Du, R. Eisenberg, Energy Environ. Sci. 2012, 5, 6012-6021.

[18] J. A. Haber, Y. Cai, S. Jung, C. Xiang, S. Mitrovic, J. Jin, A. T. Bell, J. M. Gregoire, Energy Environ. Sci. 2014, 7, 682-688.

[19] D. Friebel, M. W. Louie, M. Bajdich, K. E. Sanwald, Y. Cai, A. M. Wise, M.-J. Cheng, D. Sokaras, T.-C. Weng, R. Alonso-Mori, R. C. Davis, J. R. Bargar, J. K. Nørskov, A. Nilsson, A. T. Bell, J. Am. Chem. Soc. 2015, 137, $1305-$ 1313.

[20] M. García-Mota, A. Vojvodic, F. Abild-Pedersen, J. K. Nørskov, J. Phys. Chem. C 2013, 117, 460-465.

[21] G. Novell-Leruth, G. Carchini, N. López, J. Chem. Phys. 2013, 138, 194706.

[22] E. W. McFarland, H. Metiu, Chem. Rev. 2013, 113, 4391 -4427.

[23] K. Fominykh, P. Chernev, I. Zaharieva, J. Sicklinger, G. Stefanic, M. Döblinger, A. Müller, A. Pokharel, S. Böcklein, C. Scheu, T. Bein, D. Fattakhova-Rohlfing, ACS Nano 2015, 9, 5180-5188.

[24] J. Suntivich, E. E. Perry, H. A. Gasteiger, Y. Shao-Horn, Electrocatalysis 2013, 4, 49-55

[25] M. Wiechen, I. Zaharieva, H. Dau, P. Kurz, Chem. Sci. 2012, 3, 23302339.

[26] B. Li, F. Li, S. Bai, Z. Wang, L. Sun, Q. Yang, C. Li, Energy Environ. Sci. 2012, 5, 8229-8233.

[27] A. D. Doyle, J. H. Montoya, A. Vojvodic, ChemCatChem 2015, 7, 709709.

[28] J. J. Concepcion, R. A. Binstead, L. Alibabaei, T. J. Meyer, Inorg. Chem. 2013, 52, 10744-10746.

[29] D. K. Zhong, S. Zhao, D. E. Polyansky, E. Fujita, J. Catal. 2013, 307, 140 147.

[30] B. M. Klepser, B. M. Bartlett, J. Am. Chem. Soc. 2014, 136, 1694-1697.

[31] E. Farnetti, R. Di Monte, J. Kašpar in Inorganic and Bio-inorganic Chemistry, Vol. Il, Eolss Publishers, Oxford, 2007.

[32] A. Savini, A. Bucci, M. Nocchetti, R. Vivani, H. Idriss, A. Macchioni, ACS Catal. 2015, 5, 264-271. 
[33] S. W. Sheehan, J. M. Thomsen, U. Hintermair, R. H. Crabtree, G. W. Brudvig, C. A. Schmuttenmaer, Nat. Commun. 2015, 6, 6469.

[34] J. K. Nørskov, J. Rossmeisl, A. Logadottir, L. Lindqvist, J. R. Kitchin, T. Bligaard, H. Jónsson, J. Phys. Chem. B 2004, 108, 17886-17892.

[35] J. P. Perdew, K. Burke, M. Ernzerhof, Phys. Rev. Lett. 1996, 77, 3865 3868.

[36] G. Kresse, J. Furthmüller, Phys. Rev. B 1996, 54, 11169-11186.

[37] G. Kresse, J. Furthmüller, Comput. Mater. Sci. 1996, 6, 15-50.

[38] P. E. Blöchl, Phys. Rev. B 1994, 50, 17953-17979.

[39] H. Zhang, A. Soon, B. Delley, C. Stampfl, Phys. Rev. B 2008, 78, 045436.

[40] F. G. Sen, A. Kinaci, B. Narayanan, S. K. Gray, M. J. Davis, S. K. R. S. Sankaranarayanan, M. K. Y. Chan, J. Mater. Chem. A 2015, DOI: 10.1039/ C5A04678E

[41] A. A. Bolzan, C. Fong, B. J. Kennedy, C. J. Howard, Acta Crystallogr. Sect. B 1997, 53, 373-380.

[42] Y. Lee, J. Suntivich, K. J. May, E. E. Perry, Y. Shao-Horn, J. Phys. Chem. Lett. 2012, 3, 399-404.

[43] J. Rossmeisl, A. Logadottir, J. K. Nørskov, Chem. Phys. 2005, 319, 178 184.

[44] S. Klüpfel, P. Klüpfel, H. Jónsson, J. Chem. Phys. 2012, 137, 124102.

[45] U. Hintermair, S. M. Hashmi, M. Elimelech, R. H. Crabtree, J. Am. Chem. Soc. 2012, 134, $9785-9795$.

[46] S. Romain, L. Vigara, A. Llobet, Acc. Chem. Res. 2009, 42, 1944-1953.
[47] X. Sala, S. Maji, R. Bofill, J. García-Antón, L. Escriche, A. Llobet, Acc. Chem. Res. 2014, 47, 504-516.

[48] C. C. L. McCrory, S. Jung, J. C. Peters, T. F. Jaramillo, J. Am. Chem. Soc 2013, 135, 16977-16987.

[49] J. Rossmeisl, Z.-W. Qu, H. Zhu, G.-J. Kroes, J. K. Nørskov, J. Electroanal. Chem. 2007, 607, 83-89.

[50] I. C. Man, H.-Y. Su, F. Calle-Vallejo, H. A. Hansen, J. I. Martínez, N. G. Inoglu, J. Kitchin, T. F. Jaramillo, J. K. Nørskov, J. Rossmeisl, ChemCatChem 2011, 3, 1159-1165.

[51] S. Siahrostami, A. Vojvodic, J. Phys. Chem. C 2015, 119, 1032-1037.

[52] Y. Gong, M. Zhou, M. Kaupp, S. Riedel, Angew. Chem. Int. Ed. 2009, 48, 7879-7883; Angew. Chem. 2009, 121, 8019-8023.

[53] G. Wang, M. Zhou, J. T. Goettel, G. J. Schrobilgen, J. Su, J. Li, T. Schlöder, S. Riedel, Nature 2014, 514, 475-477.

[54] M. García-Mota, A. Vojvodic, H. Metiu, I. C. Man, H.-Y. Su, J. Rossmeisl, J. K. Nørskov, ChemCatChem 2011, 3, 1607-1611.

[55] Y.-H. Fang, Z.-P. Liu, J. Am. Chem. Soc. 2010, 132, 18214-18222.

Received: January 4, 2016

Revised: February 18, 2016

Published online on April 29, 2016 